CLINICAL STUDY

\title{
Mutational spectrum of steroid 21-hydroxylase and the genotype-phenotype association in Middle European patients with congenital adrenal hyperplasia
}

\author{
V Dolžan ${ }^{1}$, J Sólyom ${ }^{3}$, G Fekete ${ }^{3}$, J Kovács ${ }^{4}$, V Rakosnikova ${ }^{5}$, F Votava ${ }^{5}$, J Lebl ${ }^{5}$, Z Pribilincova ${ }^{6}$, \\ SM Baumgartner-Parzer ${ }^{7}, \mathrm{~S}$ Riedl ${ }^{8}$, F Waldhauser ${ }^{8}, \mathrm{H} \mathrm{Frisch}^{8}$, M Stopar-Obreza ${ }^{2}$, C Kržišnik ${ }^{2}$ and T Battelino $^{2}$ \\ ${ }^{1}$ Institute of Biochemistry, Faculty of Medicine, University of Ljubljana, Ljubljana, Slovenia, ${ }^{2}$ University Children's Hospital, Department of Pediatric \\ Endocrinology, Diabetes and Metabolic Diseases, Vrazov trg 1 SI-1000, Ljubljana, Slovenia, ${ }^{3} 2$ nd Department of Paediatrics, Semmelweis University, \\ Budapest, Hungary, ${ }^{4}$ Department of Paediatrics, University of Szeged, Szeged, Hungary, ${ }^{5}$ Department of Paediatrics, 3rd Faculty of Medicine, Charles \\ University, Prague, Czech Republic, ${ }^{6}$ Department of Paediatrics, Comenius University, Bratislava, Slovakia, ${ }^{7}$ Department of Internal Medicine III, Division \\ of Endocrinology and Metabolism, Medical University, Vienna, Austria and ${ }^{8}$ Department of Paediatrics, Medical University, Vienna, Austria
}

(Correspondence should be addressed to T Battelino; Email: tadej.battelino@mf.uni-lj.si)

\begin{abstract}
Objective: To analyze the mutational spectrum of steroid 21-hydroxylase (CYP21) and the genotypephenotype correlation in patients with congenital adrenal hyperplasia $(\mathrm{CAH})$ registered in the Middle European Society for Pediatric Endocrinology $\mathrm{CAH}$ database, and to design a reliable and rational approach for CYP21 mutation detection in Middle European populations.

Design and methods: Molecular analysis of the CYP21 gene was performed in $432 \mathrm{CAH}$ patients and 298 family members. Low-resolution genotyping was performed to detect the eight most common point mutations. High-resolution genotyping, including Southern blotting and sequencing was performed to detect CYP21 gene deletions, conversions, point mutations or other sequence changes. Results: CYP21 gene deletion and In 2 and Ile172Asn mutation accounted for $72.7 \%$ of the affected alleles in the whole study group. A good genotype-phenotype correlation was observed, with the exception of Ile172Asn and Pro30Leu mutations. In 37\% of patients low resolution genotyping could not identify the causative mutation or distinguish homozygosity from hemizygosity. Using high-resolution genotyping, the causative mutations could be identified in 341 out of 348 analyzed patients. A novel mutation Gln315Stop was found in one simple virilising CAH (SV-CAH) patient from Austria. In the remaining seven patients polymorphisms were identified as the leading sequence alteration. The presence of elevated basal and ACTH-stimulated 17-hydroxyprogesterone, premature pubarche, advanced bone age and clitoral hypertrophy directly implicated Asn493Ser polymorphism in the manifestation of nonclassical- (NC) and even SV-CAH.

Conclusions: By genotyping for the most common point mutations, CYP21 gene deletion/conversion and the 8 bp deletion in exon 3, it should be possible to identify the mutation in $94-99 \%$ of the diseased alleles in any investigated Middle European population. In patients with a mild form of the disease and no detectable mutation CYP21 gene polymorphisms should be considered as a plausible disease-causing mutation.
\end{abstract}

European Journal of Endocrinology 153 99-106

\section{Introduction}

Congenital adrenal hyperplasia $(\mathrm{CAH})$ due to steroid 21hydroxylase deficiency is one of the most common inborn endocrine disorders and is inherited in an autosomal recessive manner (1). Defects of the steroid 21-hydroxylase gene (CYP21) coding for the steroid 21-hydroxylase (21-OH) lead to various degrees of impaired cortisol and aldosterone synthesis and to androgen excess $(1,2)$. Deficiency of both cortisol and aldosterone synthesis results in salt wasting CAH (SW$\mathrm{CAH})$, usually manifesting early after birth as a salt wast- ing crisis, with ambiguous external genitalia in girls. In simple virilising $\mathrm{CAH}$ (SV-CAH) manifesting with early precocious pubarche and different degree of virilisation of external genitalia in girls, only cortisol synthesis is deficient. In nonclassical CAH (NC-CAH) the disease is mild and might not be detected until later in life $(2,3)$. However, the spectrum of disease manifestations represents rather a continuum with no clear limits. The most likely mutations in the CYP21 gene originate from the more than 98\% homologous CYP21P pseudogene $(4,5)$ and can be easily assayed on selectively amplified CYP21 gene sequences by allele-specific 
amplification or by oligonucleotide hybridisation (6). However, the occurrence of alleles with changed gene copy number, the high frequency of compound heterozygotes having inherited a different mutation in each CYP21 allele, and alleles carrying multiple mutations complicate molecular genetic diagnostics (7). The severity of the disease is determined by the activity of the less severely affected of the two alleles but different phenotypes can be associated with the same mutation and the severity of clinical manifestations may vary within the genotype $(8-10)$.

The Middle European Society for Pediatric Endocrinology (MESPE) has created a large database since 1998 containing information on 598 children with $\mathrm{CAH}$ from Austria, the Czech Republic, Hungary, Slovakia and Slovenia in order to study the endocrinological parameters, the efficiency of clinical diagnostics and the treatment and genetics of $\mathrm{CAH}$ in Middle European countries $(11-13)$. The database is described in detail elsewhere (11).

The aim of this study was to systematically analyze the mutational spectrum and the genotype-phenotype correlation in $\mathrm{CAH}$ patients and their family members registered in the MESPE-CAH database. Furthermore, we aimed to design a rational approach for CYP21 mutation detection needed for reliable pre-, peri- and postnatal diagnostics and for genetic counseling in the Middle European countries and in ethnic groups originating from the region.

\section{Subjects and methods}

\section{Study participants}

Patients from the MESPE-CAH database and their family members were invited to participate in the study and written informed consent was obtained from all the participants. The respective national ethics committees for research in medicine approved the study design. The clinical and laboratory data on the patients were available on the database. The clinical diagnosis of different types of 21-OH deficiency was made by paediatric endocrinologists based on the history, physical examination, electrolyte and hormonal data $(1,14)$. Patients were considered to have the SW form when clinical and laboratory signs of renal salt wasting were present in the first month of life; the SV form was assigned if clinical symptoms of $\mathrm{CAH}$ without SW were present before the age of puberty onset, i.e. 8 years, and the $\mathrm{NC}$ form when symptoms of androgen excess became evident during or after puberty (11). Patients without reliable clinical information were excluded from the study.

\section{Methods}

National coordinators were asked to provide peripheral blood or genomic DNA samples of patients and their first-degree relatives for genotyping. Out of $598 \mathrm{CAH}$ patients from the five Middle European countries included in the MESPE-CAH database peripheral blood or genomic DNA samples were available from 476 patients $(79.6 \%)$. Sequence analysis was used to detect CYP21 gene mutations in Austrian patients using the approach previously described (15). For patients from other countries a two-step genotyping approach was employed. Low-resolution genotyping for 8 common point mutations was performed using allele-specific polymerase chain reaction (PCR-SSP) and/or PCR and sequence specific oligonucleotide hybridisation (PCR-SSO) by participating centers (16-18). High resolution genotyping by PCR-SSP, PCR-SSO, Southern blotting and sequencing was performed in Ljubljana to detect CYP21 gene deletions, conversions, point mutations or other sequence changes when mutation could not be identified on one or both alleles by low resolution genotyping or when homozygosity could not be distinguished from hemizygosity. The genotyping approach is described in detail elsewhere $(17,18)$. The reference sequence reported by White et al. (4) was used for numbering of nucleotides and amino acids.

\section{Results}

In the present study we systematically genotyped 476 $\mathrm{CAH}$ patients from five Middle European countries. Additionally, 298 first-degree relatives (236 parents and 62 siblings) were genotyped to confirm allele segregation. The diagnosis of $\mathrm{CAH}$ could not be confirmed in 34 patients and 10 patients had $11 \beta$-hydroxylase deficiency, therefore these patients were excluded from further study.

Using low-resolution genotyping mutations could not be identified or homozygosity could not be distinguished from hemizygosity in 160 out of 432 patients (37\%). From 84 of these patients DNA was not available for further analysis. Using high-resolution genotyping, Southern blotting and sequencing the causative mutations could be identified in 341 out of $348(98.0 \%)$ patients while in the remaining seven patients polymorphisms were identified as the leading sequence alteration.

A novel mutation Gln315Stop (Fig. 1) resulting in a premature stop codon which has not been described to date in $\mathrm{CAH}$ patients, was found in a patient from Austria. The girl was diagnosed at age $4 \cdot 4$ and was clinically SV. The sequencing analysis of both parents confirmed the inheritance of a Gln315Stop mutation from her mother and of a Pro30Leu mutation from her father.

Complete genotypes and clinical phenotypes of MESPE-CAH patients are shown in Table 1. Among 348 patients 221 (63.5\%) presented with SW-CAH (92 boys and 129 girls), 92 (26.4\%) had SV-CAH (35 boys and 57 girls) and 35 (10.1\%) had NC-CAH (12 boys and 23 girls). One third of the patients were compound 
normal haplotype

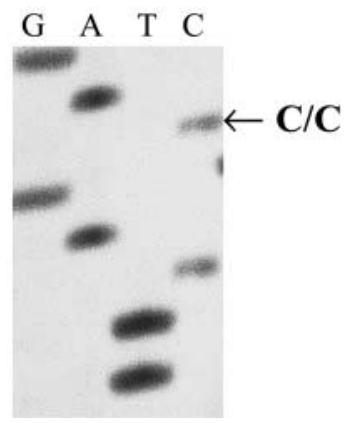

Figure 1 Sequence analysis of the GIn315 locus in exon 8 of the CYP21 gene. Arrowheads indicate the heterozygous nucleotide substitution $(\mathrm{C} \rightarrow \mathrm{T})$ from the fuctionally normal CYP21 haplotype CAG to TAC, resulting in the change of Glutamine (GIn) to a premature stop codon.

heterozygotes, having inherited a different mutation in each CYP21 allele, $43.8 \%$ of all patients were homozygous and $22.9 \%$ were hemizygous for the mutation identified. The most common mutations found in SW-CAH were In 2 (49.8\%) and CYP21 gene deletion/conversion (29.9\%). Ile172Asn was the most common mutation found in SV-CAH $(59.8 \%)$, however it was also observed in $6.8 \%$ of SW-CAH as well as in $8.3 \%$ of NC-CAH patients. Other common mutations found in SV-CAH were Pro30Leu in $16.3 \%$, a promoter conversion associated with Pro30Leu in $8.7 \%$ and In2 in $7.6 \%$ of SV patients. Together with Ile172Asn these mutations accounted for more than $90 \%$ of the SV form. The most common NC-CAH mutations were Val281Leu (41.7\%), Pro30Leu (22.2\%) and the Asn493Ser polymorphism (16.7\%) together accounting for $80 \%$ of the NC-CAH. The Val281Leu mutation also represented the least severe mutation in $4.4 \%$ of SV-CAH patients.

To analyze the genotype-phenotype correlation, CYP21 gene mutations were categorized into four groups based on in vitro established enzyme activity as described previously $(3,8,10)$. Alleles with multiple mutations were grouped according to the most severe mutation of the haplotype (Table 2). Although the impairment of enzyme activity for CYP21 gene conversion involving the promoter region alone or combined with Pro30Leu substitution has not been established in vitro these mutations were categorized in group B based on the previous reports of clinical phenotypes more severe than predicted in patients carrying these mutations $(15,18)$. As summarized in Table 2 a good genotype-phenotype correlation was observed in patients with severe mutations categorised in mutation groups 0 and A. Greater diversity of clinical phenotypes was observed in patients with less severe mutations, especially in carriers of Ile172Asn and Pro30Leu mutations, categorized in mutation groups $\mathrm{B}$ and $\mathrm{C}$, respectively. In most patients the observed phenotype matched the severity of the less affected of the two alleles,
Table 1 Genotypes and clinical phenotypes in 348 MESPE patients with 21-hydroxylase deficiency.

\begin{tabular}{|c|c|c|c|}
\hline \multirow{2}{*}{$\begin{array}{l}\text { CYP21 haplotype } \\
\text { (allele 1/allele 2) }\end{array}$} & \multicolumn{3}{|c|}{ CAH phenotype } \\
\hline & SW & SV & NC \\
\hline Del/del or conv & 61 & 0 & 1 \\
\hline Del/del 8ntG110 (ex3) & 1 & 0 & 0 \\
\hline Del/InsT307 & 1 & 0 & 0 \\
\hline Del/Gln318Stop & 1 & 0 & 0 \\
\hline Del/Arg356Trp & 1 & 0 & 0 \\
\hline $\mathrm{Del} / \mathrm{Arg} 483 \mathrm{GG} \rightarrow \mathrm{C}$ & 2 & 0 & 0 \\
\hline Small conv/conv & 4 & 0 & 0 \\
\hline Del 8ntG110 (ex3)/del 8ntG110 (ex3) & 3 & 0 & 0 \\
\hline Cluster ex6/cluster ex6 & 1 & 0 & 0 \\
\hline InsT307/small conv & 1 & 0 & 0 \\
\hline InsT307/InsT307 & 2 & 0 & 0 \\
\hline InsT307/GIn318Stop & 1 & 1 & 0 \\
\hline GIn318Stop/GIn318Stop & 1 & 0 & 0 \\
\hline Arg356Trp/small conv & 1 & 0 & 0 \\
\hline Arg356Trp/Arg356Trp & 4 & 0 & 0 \\
\hline Arg483Pro/Arg483Pro & 1 & 0 & 0 \\
\hline In2/del or conv & 36 & 1 & 1 \\
\hline In2/In2 & 62 & 5 & 0 \\
\hline In2/InsT307 & 3 & 0 & 0 \\
\hline In2/GIn318Stop & 4 & 1 & 0 \\
\hline In2/Arg483Pro & 1 & 0 & 0 \\
\hline In2/Arg483GG + C & 1 & 0 & 0 \\
\hline Prom conv + Pro30Leu/del or conv & 1 & 5 & 2 \\
\hline Prom conv + Pro30Leu/del 8ntG110 (ex3) & 1 & 0 & 0 \\
\hline Prom conv + Pro30Leu/In2 & 0 & 1 & 0 \\
\hline Prom conv + Pro30Leu/lle172Asn & 0 & 1 & 0 \\
\hline Prom conv + Pro30Leu/GIn318Stop & 0 & 1 & 0 \\
\hline Ile172Asn/del or conv & 6 & 16 & 1 \\
\hline Ile172Asn/In2 & 2 & 17 & 0 \\
\hline Ile172Asn/del 8 bp & 0 & 1 & 0 \\
\hline Ile172Asn/lle172Asn & 4 & 14 & 1 \\
\hline Ile172Asn/GIn318Stop & 2 & 3 & 1 \\
\hline Ile172Asn/Arg356Trp & 1 & 3 & 0 \\
\hline Ile172Asn/Arg483GG + C & 0 & 1 & 0 \\
\hline Pro30Leu/del or conv & 1 & 4 & 2 \\
\hline Pro30Leu/Pro30Leu & 0 & 1 & 1 \\
\hline Pro30Leu/In2 & 0 & 6 & 0 \\
\hline Pro30Leu/lle172Asn & 0 & 3 & 3 \\
\hline Pro30Leu/Val281Leu & 0 & 0 & 2 \\
\hline Pro30Leu/GIn315Stop & 0 & 1 & 0 \\
\hline Val281Leu/del or conv & 1 & 2 & 6 \\
\hline Val281Leu/In2 & 0 & 2 & 3 \\
\hline Val281Leu/Val281Leu & 1 & 0 & 1 \\
\hline Val281Leu/InsT307 & 0 & 0 & 2 \\
\hline Val281Leu/GIn318Stop & 0 & 0 & 1 \\
\hline Val281Leu/Arg356Trp & 1 & 0 & 0 \\
\hline Pro453Ser/del & 1 & 0 & 1 \\
\hline Pro453Ser/In2 & 3 & 0 & 0 \\
\hline Prom conv/del or conv & 3 & 1 & 0 \\
\hline Asn493Ser/del & 0 & 1 & 1 \\
\hline Asn493Ser/Arg356Trp & 0 & 0 & 2 \\
\hline Asn493Ser/Asn493Ser & 0 & 0 & 2 \\
\hline Asn493Ser/Asn493Ser + T-107C & 0 & 0 & 1 \\
\hline Total & 221 & 92 & 35 \\
\hline
\end{tabular}

Del, CYP21 gene deletion; large conv, large gene conversion; prom conv, gene conversion in promoter region; small conv, multiple mutations present on the same allele, conversion not detectable by PCR-SSP or Southern blot analysis; conv, large or small conversion; Ins, insertion; in2, intron 2 mutation (A,C656G); del 8ntG110, 8 bp deletion in exon 3. 
Table 2 Genotype-phenotype correlation in MESPE-CAH patients.

\begin{tabular}{|c|c|c|c|c|c|}
\hline \multicolumn{2}{|c|}{ Mutation group } & \multirow[b]{2}{*}{ Predicted phenotype } & \multicolumn{3}{|c|}{ Observed phenotype } \\
\hline Allele 1 & Allele 2 & & SW & SV & NC \\
\hline 0 & 0 & SW & 81 & 1 & 1 \\
\hline A & 0 & SW & 44 & 1 & 1 \\
\hline A & A & SW & 64 & 5 & 0 \\
\hline B & 0 & SV & 15 & 29 & 4 \\
\hline B & A & SV & 4 & 21 & 0 \\
\hline B & B & SV & 5 & 15 & 1 \\
\hline C & 0 & NC & 4 & 4 & 12 \\
\hline C & A & NC & 3 & 9 & 3 \\
\hline C & B & NC & 0 & 4 & 3 \\
\hline C & C & NC & 1 & 1 & 4 \\
\hline \multicolumn{6}{|l|}{ Not classified } \\
\hline GIn315Stop & C & & 0 & 1 & 0 \\
\hline Asn493Ser & 0 & & 0 & 1 & 2 \\
\hline Asn493Ser & Asn493Ser & & 0 & 0 & 3 \\
\hline Lys102Arg Ser268Thr & 0 & & 0 & 0 & 1 \\
\hline Total & & & 221 & 92 & 35 \\
\hline
\end{tabular}

Mutation group 0, CYP21 gene deletion, large gene conversion, 8 bp deletion in exon 3, cluster mutation in exon 6, InsT307, GIn318Stop, Arg356Trp, Arg483Pro, Arg483GG $\rightarrow \mathrm{C}$, and multiple mutations alleles containing any of these mutations; mutation group A, intron 2 mutation; mutation group B, lle172Asn, promoter conversion + Pro30Leu, promoter conversion; mutation group C, Pro30Leu, Val28Leu, Pro453Ser.

however the presence of a group 0 or A mutation on the second allele frequently resulted in a more severe clinical phenotype.

The allele frequencies of CYP21 gene mutations in MESPE-CAH patients were calculated based on systematic genotyping of 696 unrelated chromosomes. As shown in Table 3 only three mutations: CYP21 gene deletion, In2 and Ile172Asn were found to occur with a frequency higher than $10 \%$ each. Together they represented almost three quarters $(72.7 \%)$ of the affected alleles in all the populations studied. Country-specific differences were observed in the frequencies of a particular mutation. The frequency of CYP21 gene deletion was $27.1 \%$ in the whole study group and ranged from $37.2 \%$ in Slovenian patients to $13.9 \%$ in Slovak patients. The In 2 mutation with the allele frequency of $31.1 \%$ in the whole study group was the most prevalent mutation in Slovak $(50.0 \%)$ and in Hungarian patients $(35.9 \%)$ and it was the lowest in Slovenian patients (16.7\%). Similarly, Ile172Asn had the lowest allele frequency in Slovenian patients $(7.7 \%)$ while this mutation's frequency was the highest in Austrian patients (22.5\%).

Many diverse alleles with multiple mutations were found: $4.3 \%$ of all the alleles carried two mutations and $1.4 \%$ of alleles carried more than two mutations. The frequency of alleles with multiple mutations was highest among Slovenian patients (15.4\% of all alleles), where the haplotypes were confirmed by analyzing the segregation of mutations in the families. The most common mutation occurring on the same haplotype with other mutations was In $2.1 \%$ of all alleles $)$. Among 43 alleles with the Pro30Leu mutation only $26(60.5 \%)$ represented a single nucleotide substitution, while Pro30Leu and promoter conversion alone or with a third mutation occurred on 17 separate alleles $(39.5 \%)$ and represented $2.4 \%$ of all alleles.

In seven patients polymorphisms were identified to be the leading sequence alteration as the direct sequencing of all exons, introns and the proximal promoter region of CYP21 gene did not reveal any putative new mutation. Among these patients three were homo- or hemizygous for Asn493Ser and three were compound heterozygotes for this substitution. The clinical characteristics of these patients are given in Table 4. Most of the patients with Asn493Ser presented with elevated baseline or ACTH-stimulated 170HP levels, premature pubarche or advanced bone age and one girl had clitoral hypertrophy. Elevated basal $17 \mathrm{OHP}$ levels were also observed in the $\mathrm{NC}$ patient hemizygous for the Lys102Arg Ser268Thr polymorphism, who also presented with clitoral hypertrophy.

\section{Discussion}

Systematic analysis of the mutational spectrum of the CYP21 gene and the associated haplotypes was performed in 348 patients with $\mathrm{CAH}$ registered in the MESPE-CAH database. Among them 221 presented with SW-CAH, 92 with SV-CAH and 35 with NC$\mathrm{CAH}$. In a particular clinical form two to three different mutations were found in more than $80 \%$ of all haplotypes: In 2 and CYP21 gene deletion/conversion in SW-CAH, Ile172Asn and Pro30Leu with or without promoter conversion in SV-CAH and Val281Leu, Pro30Leu and Asn493Ser in NC-CAH. 
Table 3 CYP21 allele frequencies in different populations within MESPE-CAH study.

\begin{tabular}{|c|c|c|c|c|c|c|c|c|c|c|c|c|}
\hline \multirow[b]{2}{*}{ CYP21 alleles } & \multicolumn{2}{|c|}{ Austrian } & \multicolumn{2}{|c|}{ Czech } & \multicolumn{2}{|c|}{ Hungarian } & \multicolumn{2}{|c|}{ Slovak } & \multicolumn{2}{|c|}{ Slovenian } & \multicolumn{2}{|c|}{ Total } \\
\hline & $\mathrm{N}$ & $\%$ & $\mathrm{~N}$ & $\%$ & $\mathrm{~N}$ & $\%$ & $\mathrm{~N}$ & $\%$ & $\mathrm{~N}$ & $\%$ & $\mathrm{~N}$ & $\%$ \\
\hline Del & 40 & 33.3 & 55 & 28.4 & 60 & 22.2 & 5 & 13.9 & 29 & 38.2 & 189 & 28.4 \\
\hline Large conv & & & 5 & 2.6 & 5 & 1.9 & & & 5 & 6.6 & 15 & 2.2 \\
\hline Prom conv & & & 3 & 1.5 & 1 & 0.4 & 3 & 8.3 & & & 7 & 1.0 \\
\hline Pro30Leu & 11 & 9.2 & 4 & 2.1 & 8 & 3.0 & & & 3 & 3.9 & 26 & 3.7 \\
\hline $\ln 2$ & 26 & 21.7 & 63 & 32.5 & 97 & 35.9 & 18 & 50.0 & 13 & 17.1 & 217 & 31.2 \\
\hline Del 8ntG110 (ex3) & & & 3 & 1.5 & & & 4 & 11.1 & & & 7 & 1.0 \\
\hline Ile172Asn & 27 & 22.5 & 27 & 13.9 & 38 & 14.1 & 3 & 8.3 & 6 & 7.9 & 101 & 14.5 \\
\hline Cluster ex6 & & & 2 & 1.0 & & & & & & & 2 & 0.3 \\
\hline Val281Leu & 4 & 3.3 & 3 & 1.5 & 15 & 5.6 & & & 2 & 2.6 & 24 & 3.4 \\
\hline InsT307 & & & & & 10 & 3.7 & & & 1 & 1.3 & 11 & 1.6 \\
\hline Gln315Stop & 1 & 0.8 & & & & & & & & & 1 & 0.1 \\
\hline Gln318Stop & 4 & 3.3 & 6 & 3.1 & 5 & 1.9 & 1 & 2.8 & 2 & 2.6 & 18 & 2.6 \\
\hline Arg356Trp & 5 & 4.2 & 4 & 2.1 & 8 & 3.0 & & & & & 17 & 2.4 \\
\hline Pro453Ser & 1 & 0.8 & & & 3 & 1.1 & & & 1 & 1.3 & 5 & 0.7 \\
\hline Arg483Pro & 1 & 0.8 & & & & & & & & & 1 & 0.1 \\
\hline Arg483GG $\rightarrow C$ & & & 6 & 3.1 & & & & & & & 6 & 0.9 \\
\hline Asn493Ser & & & 6 & 3.1 & 2 & 0.7 & & & 2 & 2.6 & 10 & 1.4 \\
\hline \multicolumn{13}{|l|}{ Small conversions } \\
\hline Prom conv + Pro30Leu & & & 4 & 2.1 & 7 & 2.6 & & & 3 & 3.9 & 14 & 2.0 \\
\hline Prom conv + Pro30Leu + In2 & & & & & & & & & 1 & 1.3 & 1 & 0.1 \\
\hline Prom conv + Pro30Leu + Als15Thr & & & & & & & & & 2 & 2.6 & 2 & 0.3 \\
\hline Prom conv + del $8 b p$ & & & & & & & 1 & 2.8 & & & 1 & 0.1 \\
\hline In2 + Ile172Asn & & & 2 & 1.0 & 3 & 1.1 & & & & & 5 & 0.7 \\
\hline In2 + Val281Leu & & & & & 2 & 0.7 & & & & & 2 & 0.3 \\
\hline In2 + VasT307 & & & & & 1 & 0.4 & 1 & 2.8 & & & 2 & 0.3 \\
\hline In2 + Arg356Trp & & & 1 & 0.5 & 1 & 0.4 & & & & & 2 & 0.3 \\
\hline In2 + Ex6 + Val281Leu + Gln318Stop & & & & & & & & & 2 & 2.6 & 2 & 0.3 \\
\hline In2 + Val281Leu + Gln318Stop + Arg356Trp & & & & & 1 & 0.4 & & & & & 1 & 0.1 \\
\hline Ex 4-ex8 conversion & & & & & 1 & 0.4 & & & & & 1 & 0.1 \\
\hline Ile172Asn + ex6 + Pro453Ser & & & & & 1 & 0.4 & & & 1 & 1.3 & 1 & 0.1 \\
\hline Val281Leu + InsT307 + & & & & & 1 & 0.4 & & & & & 1 & 0.1 \\
\hline Gln318Stop + Arg356Trp & & & & & & & & & & & & \\
\hline InsT307 + Gln318Stop & & & & & & & & & 3 & 3.9 & 3 & 0.4 \\
\hline InsT307 + Arg356Trp & & & & & 1 & 0.4 & & & & & 1 & 0.1 \\
\hline Total small conversion alleles & & & 7 & 3.6 & 18 & 6.7 & 2 & 5.6 & 12 & 15.6 & 39 & 5.3 \\
\hline Total alleles & 120 & 100.0 & 194 & 100.0 & 270 & 100.0 & 36 & 100.0 & 76 & 100.0 & 696 & 100.0 \\
\hline
\end{tabular}

Del, CYP21 gene deletion; large conv, large gene conversion; prom conv, gene conversion in promoter region; In2, intron 2 splice site mutation (A, C656G); del 8ntG110, 8 bp deletion in exon 3; ex6, cluster mutation in exon6; Ex4-ex8 conversion, Ile172Asn + ex6 + Val281Leu + InsT307 + GIn318Stop + Arg356Trp.

We found a Gln315Stop substitution in one SV-CAH patient from Austria. This mutation has not been described to date in $\mathrm{CAH}$ patients and results in a premature stop codon. Although a functional assay has to be performed to determine the residual enzyme activity of this mutation in vitro we assume that such a mutation would completely abolish enzyme activity, similarly to the nearby Gln318Stop mutation. This would also explain a SV phenotype in this patient carrying Pro30Leu mutation on the less affected haplotype.

The large number of patients included in this study enabled us to analyze the genotype-phenotype correlation. In general a good genotype-phenotype correlation was observed in patients with severe mutations, however carriers of the Ile172Asn and Pro30Leu mutations on the less affected allele displayed a greater variability of clinical phenotypes. This phenotypic variability of Ile172Asn mutation has also been reported in other European populations showing an otherwise good correlation between the genotype and phenotype $(3,10,19,20)$. Similarly, many investigators have reported phenotypes more severe than expected in carriers of the Pro30Leu mutation $(9,10$, 15, 18, 21). The finding of the Pro30Leu mutation linked to a gene conversion in the promoter region or with an additional mutation, Ala15Thr, could explain the increased severity of phenotypes in Slovenian patients (18). The in vitro expression analysis did not demonstrate the impairment of enzyme activity by Ala15Thr mutation alone (22) but it is not excluded that this mutation has a synergistic effect on 21-hydroxylase activity when combined with the Pro30Leu mutation and/or gene conversion in the promoter region (23).

The relatively slight differences in the distribution of CYP21 mutations observed between individual countries within the Middle European region suggest 


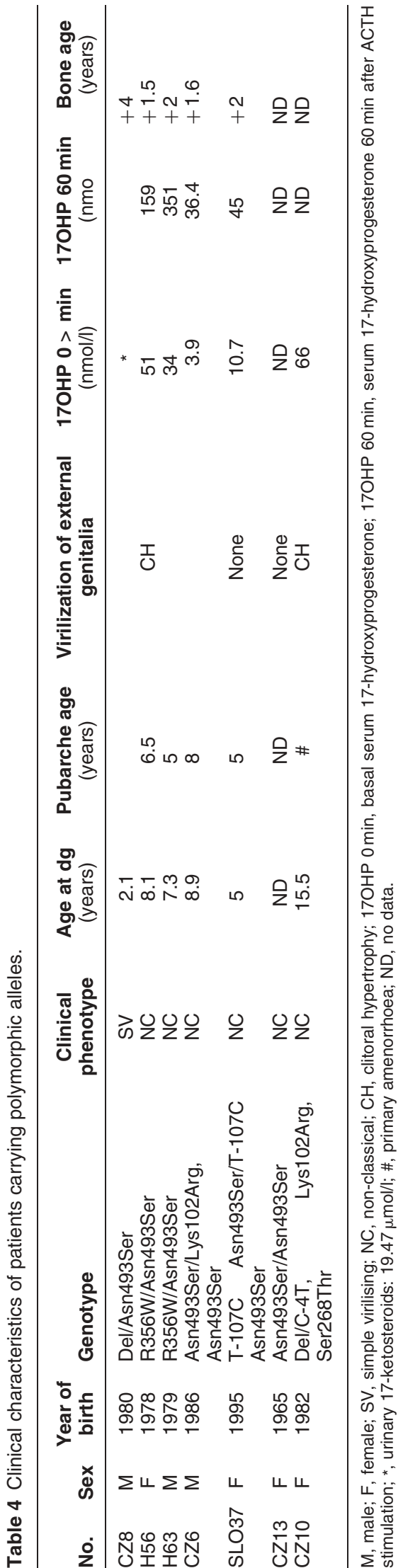

that, despite differences in ethnic origins, similar genetic mechanisms were probably involved in the transmission of the disease. A possible explanation for this may be a high degree of ethnic mixing over the centuries in some populations (16). The observed frequencies of the CYP21 gene deletion (range 13.9-37.2\%) and In 2 mutation (range 16.7-50.0\%) were comparable to the frequencies observed in most of the other European countries. In CAH patients from the Middle European populations studied, the frequencies of the Val281Leu mutation (range 1.5-5.6\%) were lower than in Italy, France and Spain (range 11.0-16.7\%), but comparable to other European countries (range 2.2-5.7\%). The frequencies of Pro30Leu in Middle European populations (range 2.1-9.2\%) were higher, particularly in Austrian CAH patients than in other European populations (range $0.3-2.7 \%)(8,10,20$, 24-26).

A high frequency of alleles with multiple mutations was found: $5.6 \%$ of the alleles in the whole study group and $15.4 \%$ of all the alleles in Slovenian patients carried two or more mutations. The clustering of point mutations on one allele has been previously reported in $1.9 \%$ of unrelated alleles in Dutch patients (20). The relatively high frequency of alleles with multiple mutations in Middle European patients compared to some other single point mutations considered to be common in CAH, such as Gln318Stop (2.6\%) and Arg 356Trp (2.4\%), demonstrates the importance of including the parents of the index case in the molecular analysis if segregation of alleles needs further determination. If families are not available, mutations can be allocated to separate alleles by allele-specific PCR amplifications (8).

By low-resolution genotyping for the eight most common CYP21 point mutations, mutations could not be identified or homozygosity could not be distinguished from hemizygosity in $37 \%$ of patients. Using high-resolution genotyping, PCR-SSP amplification and Southern blotting for the detection of CYP21 gene deletion and large gene conversions only $2 \%$ of alleles remained unidentified. Among these, direct sequencing of CYP21 identified Asn493Ser substitution as the leading sequence change in six patients. Some authors describe this substitution as a naturally occurring polymorphism (27) and some as a disease causing mutation (28) but its influence on residual enzyme activity has never been analyzed in vitro. In Mexican $\mathrm{CAH}$ patients a higher proportion of homozygosity for the Asn493Ser substitution was observed than in a healthy population (29). It was proposed that a synergistic effect between two mutations could lead to decreased enzymatic activity in CAH patients homozygous for Ser268Thr and Asn493Ser $(30,31)$, but, except in one patient with a T-107C substitution and one patient with concomitant Lys102Arg on one haplotype, the sequencing of all the exons, introns and 340 nucleotides of the proximal promoter region 
revealed no other sequence alteration on alleles characterised by Asn493Ser. The presence of elevated basal and ACTH-stimulated 170HP, premature pubarche, advanced bone age in all patients and also clitoral hypertrophy in one girl implicates a direct role of this substitution in the disease manifestation of $\mathrm{NC}$ and even SV-CAH.

Lys102Arg and Ser268Thr mutations were also reported to be normal polymorphisms, however, a synergistic effect resulting in a decreased enzymatic activity was observed when both mutations were transmitted on the same haplotype $(30,31)$. This could explain the finding of clitoral hypertrophy and elevated basal 17OHP levels in one $\mathrm{NC}$ patient hemizygous for Lys102Arg Ser268Thr substitutions.

In conclusion, our genotyping approach allowed accurate and sensitive identification of CYP21 gene mutations in $\mathrm{CAH}$ patients and their families and offered reliable information needed for diagnostics and for adequate genetic counselling in the Middle European countries and in ethnic groups originating from the region. A novel Gln315Stop mutation was identified. By genotyping for the most common point mutations, CYP21 gene deletion/conversion and the 8 bp deletion in exon 3, it should be possible to identify the responsible mutation in $94-99 \%$ of the diseased alleles in any investigated population. In patients with a mild form of the disease and a normal genotype at all positions, CYP21 gene polymorphisms such as Asn493Ser should be considered as a plausible disease causing mutation.

\section{Acknowledgements}

This study was supported by grants from the Slovenian Ministry for Education, Science and Sport (\# J3-7880, J3-3096, J3-6072, J3-1196; P1-0170), the Hungarian National Scientific Foundation (OTKA T-037559) and CEEPUS (SI-013). The contribution of Anna Ferenczi, 2nd Department of Paediatrics, Semmelweis University, Budapest to the genotyping of Hungarian $\mathrm{CAH}$ patients is greatfully acknowledged. Special thanks to Jurka Ferran, University Children's Hospital, Ljubljana for her expert technical assistance. The assistance of Regina Sepsiova, Bratislava, Slovakia is greatfully acknowledged. The MESPE-CAH study group consists of the following physicians who contributed patients' data - Austria: P Blümel, $\mathrm{H}$ Frisch, $\mathrm{K}$ Kapelari, E Plöchl, K Schmitt and F Waldhauser; Czech Republic: O Hníková, B Kalvachová, J Klabochová, S Koloušková, J Lebl, L Lisá, V Procházková, S Prùhová, R Prùsa, J Skvor, M Šnajderová, J Venhácová, F Votava, J Zapletalová and J Zeman; Hungary: É Erhardt, Z Halász, I Ilyés, J Kovács, K Láng, E Nagy, T Niederland, F Péter, L Ságodi, G Soltész, E Sólyom, J Sólyom, L Szabó and P Szüts; Slovakia: S Bielikova, M Debreova, J Javorkova, L Kostalova, M Kusekova, Z Misikova,
Z Priblincova, J Strnova, Z Simekova and D Trezova; Slovenia: T Battelino, N Bratanič, V Dolžan, C Kržišnik, Mojca Zerjav-Tansek, B Repič-Lampret, M StoparObreza, and K Trebušak.

\section{References}

1 White PC, New MI \& Dupont B. Congenital adrenal hyperplasia. New England Journal of Medicine 1987316 1519-1524.

2 White PC \& New MI. Genetic basis of endocrine disease 2: congenital adrenal hyperplasia due to 21-hydroxylase deficiency. Journal of Clinical Endocrinology and Metabolism 1992 74 6-11.

3 Speiser PW, Dupont J, Zhu D, Serrat J, Buegeleisen M, TusieLuna MT, Lesser M, New MI \& White PC. Disease expression and molecular genotype in congenital adrenal hyperplasia due to 21-hydroxylase deficiency. Journal of Clinical Investigations $199290584-595$.

4 White PC, New MI \& Dupont B. Structure of human steroid 21-hydroxylase genes. PNAS 198683 5111-5115.

5 Higashi Y, Yoshioka H, Yamane M, Gotoh O \& Fujii-Kuriyama Y. Complete nucleotide sequence of two steroid 21-hydroxylase genes tandemly arranged in human chromosome: a pseudogene and a genuine gene. PNAS $1986832841-2845$.

6 Urabe K, Kimura A, Harada F, Iwanaga T \& Sasazuki T. Gene conversion in steroid 21-hydroxylase genes. American Journal of Human Genetics $1990 \mathbf{4 6} 1178-1186$.

7 Helmberg A, Tusie-Luna MT, Tabarelli M, Kofler R \& White PC. R339H and P453: CYP21 mutations associated with nonclassic steroid 21-hydroxylase deficiency that are not apparent gene conversions. Molecular Endocrinology 19926 1318-1322.

8 Wedell A, Thilen A, Ritzen EM, Stengler B \& Luthman H. Mutational spectrum of the steroid 21-hydroxylase gene in Sweden: implications for genetic diagnosis and association with disease manifestation. Journal of Clinical Endocrinology and Metabolism 199478 1145-1152.

9 Wilson RC, Mercado AB, Cheng KC \& New MI. Steroid 21hydroxylase deficiency: genotype may not predict phenotype. Journal of Clinical Endocrinology and Metabolism $1995802322-2329$.

10 Krone N, Braun A, Roscher AA, Knorr D \& Schwarz P. Predicting phenotype in steroid 21-hydroxylase deficiency?. Comprehensive genotyping in 155 unrelated, well defined patients from Southern Germany. Journal of Clinical Endocrinology and Metabolism 2000 85 1059-1065.

11 Kovacs J, Votava F, Heinze G, Solyom J, Lebel J, Priblincova Z, Frisch H, Battelino T, Waldhauser F \& the MEWPE-CAH study group. Lessons from 30 years of clinical diagnosis and treatment of congenital adrenal hyperplasia in five middle European countries. Journal of Clinical Endocrinology and Metabolism 2001 $862958-2964$.

12 Hargitai G, Solyom J, Battelino T, Lebl J, Pribilincova Z, Hauspie R, Kovacs J, Waldhauser F \& Frisch H. The MEWPE-CAH study group. Growth patterns and final height in congenital adrenal hyperplasia due to classical 21-hydroxylase deficiency. Hormone Research 200155 161-171.

13 Frisch H, Waldhauser F, Lebl J, Solyom J, Hargitai G, Kovacs J, Priblincova Z, Krzisnik C \& Battelino T. For the MEWPE-CAH study group. Congenital adrenal hyperplasia: lessons from a multinational study. Hormone Research 200257 (Suppl 2) 95-101.

14 New MI, Lorenzen F, Lerner AJ, Kohn B, Oberfield SE, Pollack MS, Dupont B, Stoner E, Levy DJ, Pang S \& Levine LS. Genotyping steroid 21-hydroxylase deficiency: hormonal reference data. Journal of Clinical Endocrinology and Metabolism 198357 320-326.

15 Baumgartner-Parzer SM, SchulzeE, Waldhausl W, Pauschenwein S, Rondot S, Nowotny P, Meyer K, Frisch H, Waldhauser F \& Vierhapper H. Mutational spectrum of the steroid 21-hydroxylase gene in Austria: identification of a novel missense mutation. Journal of Clinical Endocrinology and Metabolism 200186 4771-4775. 
16 Ferenczi A, Garami M, Kiss E, Pek M, Sasvari-Szekely M, Barta C, Staub M, Solyom J \& Fekete G. Screening for mutations of 21-hydroxylase gene in Hungarian patients with congenital adrenal hyperplasia. Journal of Clinical Endocrinology and Metabolism $1999842369-2372$.

17 Dolžan V, Preželj J, Vidan-Jeras B \& Breskvar K. Adrenal 21 hydroxylase gene mutations in Slovenian hyperandrogenic women: evaluation of corticotrophin stimulation and HLA polymorphisms in screening for carrier status. European Journal of Endocrinology $1999 \mathbf{1 4 1} 132-139$.

18 Dolžan V, Stopar-Obreza M, Žerjav-Tanšek M, Breskvar K, Kržišnik C \& Battelino T. Mutational spectrum of congenital adrenal hyperplasia in Slovenian patients: a novel Ala15Thr mutation and Pro30Leu within a larger gene conversion associated with a severe form of the disease. European Journal of Endocrinology 2003 $149137-144$.

19 Jaaskelainen J, Levo A, Voutilainen R \& Partanen J. Populationwide evaluation of disease manifestation in relation to molecular genotype in steroid 21-hydroxylase (CYP21) deficiency: good correlation in a well defined population. Journal of Clinical Endocrinology and Metabolism 199782 3293-3297.

20 Stikkelbroeck NMML, Hoefsloot LH, de Wijs IJ, Otten BJ, Hermus ARMM \& Sistermans EA. CYP21 gene mutation analysis in 198 patients with 21hydroxylase deficiency in The Netherlands: six novel mutations and a specific cluster of four mutations. Journal of Clinical Endocrinology and Metabolism $2003 \mathbf{8 8}$ $3852-3859$

21 Tusie-Luna MT, Speiser PW, Dumic M. New MI \& White PC. A mutation (Pro30 to Leu) in CYP21 represents a potential nonclassic steroid 21-hydroxylase deficiency allele. Molecular Endocrinology 19915 685-692.

22 Barbaro M, Lajic S, Baldazzi L, Balsamo A, Pirazzoli P, Cicognani A, Weddel A \& Cacciari E. Functional analysis of two recurrent amino acid substitutions in the CYP21 gene from Italian patients with congenital adrenal hyperplasia. Journal of Clinical Endocrinology and Metabolism 200489 2402-2407.

23 Nikoshkov A, Lajic S, Holst M, Wedell A \& Luthman H. Synergistic effect of partially inactivating mutations in steroid 21-hydroxylase deficiency. Journal of Clinical Endocrinology and Metabolism 199782 194-199.
24 Balsamo A, Cacciari E, Baldazzi L, Tartaglia L, Cassio A, Mantovani V, Piazzi S, Cicognani A, Pirazzoli P, Mainetti B \& Zappulla F. CYP21 analysis and phenotype/genotype relationship in the screened population of the Italian emigliromagna region. Clinical Endocrinology 200053 117-125.

25 Lako M. Ramsden S, Campbell RD \& Strachan T. Mutation screening in British 21-hydroxylase deficiency families and development of novel microsatellite based approaches to prenatal diagnosis. Journal of Medical Genetics 199936 119-124.

26 Barbat B, Bogyo A, Raux-Demay MC, Kuttenn F, Boue J, SimonBouy B, Serre JL \& Mornet E. Screening of CYP21 gene mutations in 129 French patients affected by steroid-21-hydroxylase deficiency. Human Mutation 19955 126-130.

27 Weddel A \& Luthman H. Steroid 21-hydroxylase (P450c21): a new allele and spread of mutations through the pseudogene. Human Genetics 199391 236-240.

28 Ordonez-Sanchez ML, Ramirez-Jimenez S, Lopez-Gitierrez AU, Riba L, Gamboa-Cardiel S, Cerrillo-Hinojosa M, AltamiranoBustamante N, Caldaza-Leon R, Robles-Valdes C, MendozaMorfin F \& Tusie-Luna MT. Molecular genetic analysis of patients carrying steroid 21-hydroxylase deficiency in the Mexican population: identification of possible new mutations and high prevalence of apparent germ-line mutations. Human Genetics 1998 $102170-177$.

29 Rodrigues NR, Dunham I, Yu CY, Carroll MC, Porter RR \& Campbell RD. Molecular characterization of the HLA-linked steroid 21-hydroxylase B gene from an individual with congenital adrenal hyperplasia. EMBO Journal 19876 1653-1661.

30 Asanuma A, Ohura T, Ogawa E, Sato S, Igarashi Y, Matsubara Y \& Iinuma K. Molecular analysis of Japanese patients with steroid 21-hydroxylase deficiency. Journal of Human Genetics $1999 \mathbf{4 4}$ $312-317$.

31 Wu D \& Chung BC. Mutations of P-450c21 (steroid 21-hydroxylase) at $\mathrm{Cys}^{428}$. Val $^{281}$ and $\mathrm{Ser}^{268}$ result in complete, partial, or no loss of enzymatic activity, respectively. Journal of Clinical Investigations $1991 \mathbf{8 8} 519-523$.

Received 21 December 2004

Accepted 7 April 2005 